patient in the greater proportion of cases and it ought not to depress his spirits, nor is there cause for apprehension either for the present or for the future."

Oct. $23 r d, 1905$.

I am, Sirs, yours faithfully, S. W.

\section{DISEASES OF DISEASE GERMS.}

\section{To the Editors of THE LANCET.}

SiRs,-In my address at the Medical Society which you published in THE LANCET of Oct. 14th I mentioned that a doctor in South Africa had said to me that "the study of the diseases of disease germs may one day become one of the most profitable fields of research." As you have honoured this statement with your approval I think it only right to mention that its author is Dr. A. H. Watkins of Kimberley, with whom I had the pleasure of staying during the visit of the British Association to that town.

I am, Sirs, yours faithfully,

Stratford-place, W., Oct. 24th, 1905.

LAUder BRUnton.

\section{THE PREVENTION OF CONSUMPTION.}

\section{To the Editors of THE LANCET.}

Sirs,-In the numerous letters and articles which have appeared in your columns on this subject all the writers are agreed on the advisability of sanatorium treatment for early cases of phthisis. But few do more than merely mention what appears to me to be of at least equal importancenamely, the treatment of advanced cases. Surely those cases with extensive disease, profuse expectoration, and innumerable bacilli are much more dangerous to the community than the early cases with few bacilli and little or no expectoration. And yet no provision is made for them. Numbers of advanced cases apply for admission to sanatoriums and chest hospitals only to be told that they are too bad to be taken in. Where can they go to? General hospitals will not have them, sanatoriums and special hospitals refuse them, and there remains only the workhouse infirmary. Rather than send them there, their relatives and friends make heroic sacrifices and nurse them in their own homes where the poor sufferers end their days without the comforts of good nursing and medical attention so easily provided in hospitals, and the self-sacrificing relatives themselves fall victims to the same disease. And so is consumption spread.

What is the remedy for this? Every large town should have a special hospital for consumption. To these hospitals all cases of phthisis should be admitted. Any cases which in the opinion of the experienced physician in charge had so small an extent of disease as to merit hope of permanent recovery could be sent on to sanatoriums. All other cases should be retained in the hospital. Many of them would improve to a certain extent-since open-air treatment, even in advanced cases, lessens the cough, stops the night sweats, aids sleep, and improves digestion-and could be sent home, having been taught how best to relieve their own sufferings and how to avoid being a source of danger to their neighbours, and knowing that when they relapsed they could return to the hospital to be again patched up or to end their days. These hospitals need not be expensive buildings standing in extensive grounds. Plain buildings with balconies are all that would be required. They should be in the town itself to avoid the fatigue of railway journeys and to enable patients to be visited by their friends. The experience of the Victoria Park, City Road, and Brompton Hospitals shows how much phthisical patients benefit by open-air treatment even in London. If possible they might be built overlooking a public park or open space, or at least in a situation where the surrounding houses are not high. In order to draw cases from all classes certain wards might be reserved for patients willing to pay $10 s ., £ 1$, or more per week, thus providing a certain amount of social differentiation. But no cases should be refused.

By these means the advanced and dangerously infective cases would be isolated; their friends and relatives instructed in hygiene and the prevention of phthisis; sanatoriums would be relieved of the hopeless cases on which they spend so much money at present and would be able to devote themselves entirely to genuine early cases; and, lastly, the unfortunate sufferers from advanced phthisis would have a refuge where they could be relieved of much of the suffering and discomfort which they are at present doomed to endure. And in this way much would be done for both the prevention and the cure of consumption. In conclusion, let me relate the following case. There is at present in a consumption hospital a young girl who has phthisis. It is possible that in her case the disease may be arrested and she will be sent home. She lives with her mother who has advanced phthisis. One brother and one sister have already died from phthisis. How can she hope to escape reinfection? There is still another younger sister living at home who is not at present known to have phthisis. What chance has she of escaping the fate of her brother and sisters?

I am, Sirs, yours faithfully,

Oct. 7th, $1905 . \quad$ LEONARD CROSSLEY, M.D. Edin.

\section{ETHYL CHLORIDE AS A. GENERAL AN ESTHETIC.}

To the Editors of THE LANCET.

SIRS, - I have just read the reprint of Dr. W. J. McCardie's excellent paper in THE LANCET of Oct. 7th, on Ethyl Chloride as a General Anæsthetic, and can most decidedly give my experience in favour of the drug. On Sept. 8th last I was anæsthetised at the Private Hospital, Newhall-street, Birmingham, for an operation for gall-stones by Mr. Jordan Llojd. I may say that I was not in any state of fear when $I$ lay on the operating table, and I am for the most part a water drinker because I am gouty but I did what Dr. McCardie told me to do and that was to breathe quietly. On the second inhalation I found the anæsthetic effect commencing and after the fourth inhalation I was completely unconscious. This would make the time for securing unconsciousness from ten to 12 seconds. I know I had time after the second inhalation to put my hands under my thighs in case of my struggling. I can state that the pleasant, quiet, and the rapidly increasing state of unconsciousness during the administration by Dr. McCardie was, to my surgical mind, a perfect method of anæsthesia. For the remainder of the time, the operation taking about three-quarters of an hour, I understand ether and chloroform were used.

I am, Sirs, yours faithfully,

Windfield, Co. Galway, Oct. 19th, 1905. W. PUGIN Thornton.

\section{THE RATIONAL TREATMENT OF RUNNING EARS.}

\section{To the Editors of THE LANCET.}

SIRs,-Whatever the defects of my book, I have a right to complain of your reviewer whose review is a deliberate misrepresentation as may easily be proved. He begins : "This pamphlet by Mr. Faulder White is stated by him to be a public protest against the dangers of intra-meatal operations." The chief object of my publication being to show the safety of such operations, I never made any statement of the kind. He continues : "With regard to Mr. White's method of otectomy it is to be noted that removal of the larger ossicles only is meant." My description of otectomy on pp. 30 and 31 shows that this is far from being the case and such an assertion on the part of your reviewer is difficult to understand or to excuse. As to my socalled abhorrence of the radical operation, I certainly share the opinion of a leading London surgeon who wrote to me, " $I$ quite agree, too much heroic drilling and gouging," but I have not denied its being called for in certain cases where neglect has led to serious complications. Your reviewer must know that this very book gives cases in which I have performed it. But his only object seems to be to discredit me at any cost of truth. He kindly goes on to say: "Mr. White has for many years advocated certain methods of treatment which have not been accepted by the profession at large. On this point perhaps I am better informed than your reviewer but I will now merely say that it is not yet two years since I first wrote an article on otectomy and that those who have seen most of the results of my treatment are most appreciative.

After all, my methods are of chief interest in their results but your unfriendly critic has nothing to say of the long series of successful cases-successful after other methods had failed to cure. I think I have said enough to convince you that I have been seriously misrepresented on matters of fact 
and for this reason have confidence that as a mere matter of justice you will publish this letter. I am, Sirs, yours faithfully,

Coventry, Oct. 8th, 1905.

F. FA ULDER WHITE.

** Our reviewer writes: "I need hardly assure you that Mr. White is wrong in imputing deliberate misrepresentation to the reviewer of his pamphlet. By an oversight the words 'the common teaching of' were omitted before 'the dangers,' \&c., in the second line of the notice, as might have been guessed from the agreement with $\mathrm{Mr}$. White that is implied in the next paragraph. Mr. White is wrong to say that he is misrepresented as to otectomy and I refer him to p. 14 of his pamphlet, the teaching of which is only partially modified on p. 30 , and not in the pamphlet proper, but in a reprint of a paper read before the British Medical Association. With regard to Mr. White's views on the mastoid operation I stated the impression that I derived from his own words and looking again (at p. 11, for example) I do not see any misrepresentation. In respect of the time during which Mr. White has been engaged in promulgating his views, he says on p. 5: 'I have received of late a number of letters from medical men asking for the literature of my methods of treatment of otorrhœa. Such literature as I am responsible for is scattered amongst old numbers of various medical papers and sundry pamphlets. ..... I am now publishing a recapitulation of the work done by me in this direction.' I believed what he said and would suggest, if the words are not to be taken literally, that in any future edition of his work the statement should be deleted. But I would refer him to the pages of THE LANCET-a letter published in 1899 (Jan. 21st, p. 191). The reference in the review to the methods which he advocates did not take into account his method of otectomy only."

\section{AN ESPERANTO SOCIETY FOR MEDICAL MEN.}

To the Editors of THE LANCET.

SIRS,-There are many medical men in this country who would gladly take a keener interest in medical affairs in other parts of the world but who are debarred on account of the impossibility of devoting enough time to the study of one or more foreign languages. They are thus prevented from enjoying the pleasures of social intercourse with French, German, or other foreign practitioners, nor can they read foreign original contributions to medical literature. Now that Dr. Zamenhof has given us a practical international language which, whilst admirably adapted for the purpose, is yet immeasurably easier to acquire than any continental tongue, medical men abroad are rapidly availing themselves of this opportunity for coming into closer touch with each other. Whilst we in this country are cautious in regard to innovations which promise such far-reaching effects, the language is spreading amongst us and with a view to utilise its possibilities for international intercourse a society or group has been formed for English-speaking medical men. This society will act as a national centre for bringing its members into touch with foreign practitioners, for facilitating the interchange of friendly visits, for securing international correspondence, literature, and magazines, and will work with the French and other medical groups generally in advancing the international entente. All medical men who feel the need for a simple international tongue are invited to join this group. I am, Sirs, yours faithfully,

E. T. WHITAKER,

White Lodge, Shrewsbury, Oct. 16th, 1905. Secretary of the Group.

\section{THE PRESENT STATE OF MENICAL PRAC-} TICE IN THE RHONDDA VALLEY, SOUTH WALES.

To the Editors of THE LANCET.

SiRs,-It was with considerable interest that $I$ read your correspondent's article hereon in a recent issue of
THE LANCET. I have always been surprised that in spite of the increase of the number of "ethical" divisions of the British Medical Association throughout the kingdom during the last few years the condition of the medical profession in South Wales has not long since been examined and discussed in the medical periodicals.

I am in thorough agreement with your correspondent's facts as to the methods and practices in colliery districts in South Wales, particularly in the Rhondela and Aberdare Valleys, and speak with the authority of several years' experience as an assistant officer in those places. My experience in that capacity has convinced me that the bed-rock of the discontent prevailing between the miners and our profession is the "monopoly" principle. This undoubtedly is the curse of the system.

Originally the appointment of medical officers was, for the most part, made by the proprietors of the works or their representatives. Sooner or later after appointment the medical officer gradually gave more and nuore of his time and attention to develop his private practice and to accom. plish this more and more of his "club" practice had to be and was, relegated to his assistants. As this went on and as the development of the private practice became more apparent and flagrant the miners, tardy though they were in making the discovery, noted the injustice and realised at last how this behaviour on the part of the medical officer affected them. Countless were the cases when the chief medical officer unflinchingly refused to pay a night visit to a "club" patient. Invariably the assistant had to go unless the patient were an "official" at the works. The chief medical officer's salary (a very handsome one, as a rule) was secured by the poundage system at the works' office. With this as a good asset he would be able to give less service to his secured "club" practice and pay more attention to the private practice. His private practice gradually develops and ultimately yields a handsome return. Nevertheless, I have known instances in the smaller colliery districts where, as your correspondent states, many private patients have never received an account for services rendered by the chief medical officer at the colliery. But the reasons for this generally lie in the discontent of the miners in those districts, which discontent is often allayed by the so-called "private" patients who, in one way or another, use their influence to quell the discontent on the principle of quid pro quo.

The fact is, Sirs, that the cbief medical officer, having once secured a monopoly, in most cases develops a falsely independent and highly autocratic spirit in his dealings with the miners. It is this spirit which fans the discontent into flame and leads to the constant discussion among the workmen of want of attention or treatment in particular cases which so often arise. Other complaints constantly heard are that the chief medical officer will not pay a night visit to $a$ club patient when requested. The inevitable result is that the workmen devise a scheme for remedying the evils from which they suffer. Formerly these grievances were not taken notice of because they were instantly hushed up by the in terference of the officials at the works at the request of the chief medical officer. Consequently, the private practitioner was called in and the workmen then rightly considered that they were paying "twice over"-i.e., to the "works doctor" under the poundage and also to the private practitioner So much for the origin of the "schemes" which one hears of so much in these days-schemes which, I repeat, are due largely, if not entirely, to the abuses of the chief medical officers which I have detailed above. The schemes are the workmen's "retaliation" in return for the "monopoly" of the chief medical officers at colliery districts.

With regard to the "remedy" suggested by your correspondent and by "Private Practitioner" I entirely disagree with them, because it seems to me that their remedy is more open to abuse, if possible, than the state of things already existing, while it opens up fresh avenues for practices of a "shady" character. To illustrate what I mean, take a colliery district, say, where 1200 men are emploved. Let us consider that $\mathrm{A}, \mathrm{B}$, and $\mathrm{C}$ are the three professional men by whom each of the men may choose to be attended. As a rule the income of $A, B$, and $C$ from this colliery will depend upon the good opinion the workmen bave of them, professionally or otherwise. At the end of the first quarter, say, A's retinue at the works numbers 600 while the remaining 600 pay to $B$ and $C$. B and $C$ are dissatisfied and, Sirs, to my knowledge in snch cases they very soon by hook or by crook ingratiate themselves into the good opinion of the 